\title{
Collagen Membrane for Guided Cortical Bone Regeneration: Characterization, Preclinical and Proof of Concept Clinical Studies
}

\section{Brent Allan}

Centre for Orthopaedic Research, Faculty of Health and Medical Sciences, Crawley, Western Australia, Australia, 6009

\section{Rui Ruan}

Centre for Orthopaedic Research, Faculty of Health and Medical Sciences, Crawley, Western Australia, Australia, 6009 https://orcid.org/0000-0003-4947-3071

\section{Euphemie Landao-Bassonga}

Centre for Orthopaedic Research, Faculty of Health and Medical Sciences, Crawley, Western Australia, Australia, 6009

\section{Nicholas Gillman}

Griffith University School of Medicine, Gold Coast, Queensland, Australia, 4222

\section{Tao Wang}

Centre for Orthopaedic Research, Faculty of Health and Medical Sciences, Crawley, Western Australia, Australia, 6009

\section{Junjie Gao}

Centre for Orthopaedic Research, Faculty of Health and Medical Sciences, Crawley, Western Australia, Australia, 6009

\section{Yonghua Ruan}

Department of Pathology, Kunming Medical University, Kunming, Yunnan Province, China, 650500

\section{Yuan Xu}

Medical Imaging Center, The First Affiliated Hospital, Jinan University, Guangzhou, Guangdong, China, 510632

\section{Mithran Goonewardene}

Orthodontics, Dental School, Faculty of Health and Medical Sciences, The University of Western Australia, Nedlands, Western Australia, Australia, 6009

\section{Clair Lee}

Orthocell Ltd., Murdoch, Western Australia, Australia, 6150

\section{Minghao Zheng ( $\nabla$ minghao.zheng@uwa.edu.au )}

Centre for Orthopaedic Research, Faculty of Health and Medical Sciences, Crawley, Western Australia, Australia, 6009 https://orcid.org/0000-0003-1185-4768 
Research

Keywords: Collagen membrane, guided bone regeneration, animal study, clinical trial, dental implant, bone defect

Posted Date: May 13th, 2020

DOl: https://doi.org/10.21203/rs.3.rs-26801/v1

License: (c) (i) This work is licensed under a Creative Commons Attribution 4.0 International License.

Read Full License 


\section{Collagen Membrane for Guided Cortical Bone Regeneration: Characterization, Preclinical and}

\section{Proof of Concept Clinical Studies}

Brent Allan ${ }^{1,2,3^{*}}$, Rui Ruan ${ }^{1, *}$, Euphemie Landao-Bassonga ${ }^{1}$, Nicholas Gillman ${ }^{4}$, Tao Wang ${ }^{1}$, Junjie Gao ${ }^{1}$, Yonghua Ruan ${ }^{5}$, Yuan $\mathrm{Xu}^{6}$, Mithran Goonewardene ${ }^{3}$, Clair Lee ${ }^{7}$, Minghao Zheng ${ }^{1,8 \#}$

1. Centre for Orthopaedic Research, Faculty of Health and Medical Sciences, Crawley, Western Australia, Australia, 6009

2. Oral and Maxillofacial Department, St John of God Subiaco Hospital, Subiaco, Western Australia, Australia, 6008

3. Orthodontics, Dental School, Faculty of Health and Medical Sciences, The University of Western Australia, Nedlands, Western Australia, Australia, 6009

4. Griffith University School of Medicine, Gold Coast, Queensland, Australia, 4222

5. Department of Pathology, Kunming Medical University, Kunming, Yunnan Province, China, 650500

6. Medical Imaging Center, The First Affiliated Hospital, Jinan University, Guangzhou, Guangdong, China, 510632

7. Orthocell Ltd., Murdoch, Western Australia, Australia, 6150

8. Perron Institute for Neurological and Translational Science, Nedlands, Western Australia, Australia, 6009.

* These authors contributed equally to this work

\# Corresponding author. Email: minghao.zheng@uwa.edu.au Phone: +61 (08) 9464050 Fax: +61 (08)

93463210

Contacts for the authors

Brent Allan - Phone: +61 (08) 93883999 Email: brent.allan@research.uwa.edu.au

Rui Ruan - Phone: +61 411792108 Email: chris.ruan@uwa.edu.au

Euphemie Landao-Bassonga - Email: euphemie.landao@uwa.edu.au

Nicholas Gillman - Phone: +61 406365494 Email: nicholas.gillman@griffithuni.edu.au

Tao Wang- Phone: +61 435035730 Email: tao.wang@uwa.edu.au

Junjie Gao - Phone: +61 420275812 Email: junjie.gao@perron.uwa.edu.au

Yonghua Ruan - Phone: +86 13078747528 Email: rryyhhen@163.com

Yuan Xu - Phone: +86 13531151242 Email: xuyuan emma 2017@,163.com

Mithran Goonewardene - Phone+61 419191267 Email: mithran.goonewardene@uwa.edu.au

Clair Lee- Email: clair@orthocell.com.au

Minghao Zheng - Phone: +61 (08) 9464050 Email: minghao.zheng@uwa.edu.au 
Abstract

Background: Treatment of cortical bone defects is a clinical challenge. Guided bone regeneration (GBR), commonly used in oral in maxillofacial dental surgery, may show promise for orthopedic application in repair of cortical defects. However, a limitation in the use of GBR for cortical bone defects is the lack of an ideal scaffold that provides sufficient mechanical support to bridge the cortical bone with minimal interference in the repair process. We have developed a new collagen membrane, CelGro ${ }^{\mathrm{TM}}$, for use in GBR. We report the material characterisation of CelGro ${ }^{\mathrm{TM}}$, and evaluate the performance of $\mathrm{CelGro}^{\mathrm{TM}}$ in translational preclinical and clinical studies.

Methods: Scanning electron microscopy (SEM), micro computed tomography (micro-CT) and transmission electron microscopy (TEM) were used to examine the structural morphology of CelGro $^{\mathrm{TM}}$. Purity and biochemical composition of CelGro ${ }^{\mathrm{TM}}$ was evaluated by Western-blot, immunohistochemistry and confocal microscopy. Physical and chemical properties of CelGro ${ }^{\mathrm{TM}}$ were examined and compared with another commercially available collagen membrane. The pre-clinical evaluation was conducted using a cortical bone defect model in the New Zealand white rabbit. Cortical bone regeneration in defects of the femoral diaphysis were evaluated at 30 days and 60 days after intervention, by micro-CT and histology. A clinical study to evaluate the performance of $\mathrm{CelGro}^{\mathrm{TM}}$ in GBR for treatment of bone augmentation surrounding dental implants was also performed. The clinical outcomes were evaluated by semi quantitative tissue condition assessments and cone-beam computed tomography (CBCT) scan.

Results: CelGro ${ }^{\mathrm{TM}}$ has a bilayer structure of different fibre alignment and is composed almost exclusively of type I collagen. CelGro ${ }^{\mathrm{TM}}$ was found to be completely acellular and a clinically significant xenoantigen, $\alpha$-gal, was not detected. CelGro ${ }^{\mathrm{TM}}$ displayed less deformity and better mechanical strength as compared to Bio-Gide ${ }^{\circledR}$. In the preclinical study, CelGro ${ }^{\mathrm{TM}}$ demonstrated enhanced bone-modelling activity and cortical bone healing. Micro-CT evaluation showed early bony bridging over the defect area 30 days post-operatively, and nearly complete restoration of mature cortical bone at the bone defect site 60 days postoperatively. Histological analysis at day 60 after surgery further confirmed that CelGro ${ }^{\text {TM }}$ enables bridging of the cortical bone defect by induction of newly-formed cortical bone. It appears that $\mathrm{CelGro}^{\mathrm{TM}}$ showed better cortical alignment and reduced porosity at the defect interface compared to Bio-Gide ${ }^{\circledR}$. Owning the fact that selection of orthopedic patients with cortical bone defects is complex, we conducted the proof of concept clinical study in a total of 16 dental implants which were placed in 10 participants receiving GBR. The results showed that there were with no complications or adverse events observed. CBCT evidenced efficiency of the CelGro ${ }^{\mathrm{TM}}$ scaffold for GBR for the dental implants, showing significantly decreased 
distance from the implant shoulder to first bone/implant contact (DIB) and increased horizontal thickness of facial bone wall (HT).

Conclusion: The findings of our study demonstrate that CelGro ${ }^{\mathrm{TM}}$ is an ideal membrane for GBR not only in oral maxillofacial reconstructive surgery but also in orthopedic applications.

\section{KEYWORDS}

Collagen membrane, guided bone regeneration, animal study, clinical trial, dental implant, bone defect

\section{Background}

Critical bone defects impair biomechanics and structural stability of the skeleton, leading to poor mobility, ongoing functional deficits and an overall decrease in quality of life. Bone 
defects may be primary, as a result of trauma, or secondary to diseases including tumour, infection, rheumatoid arthritis and renal failure $(1,2)$. Defects in the diaphysis of the long bone is one of the common defects in orthopedic clinics (3). Due to a relatively poor blood supply compared to the epiphysis and metaphysis, diaphyseal injuries are at higher risk of nonunion as a result of inadequate vascularization and gapping at the defect site. Clinically, treatment of cortical bone defects is always a challenge. The current standard of care generally employs bone grafting techniques which are associated with high infection risk, sub-optimal osteointegration and the need for extensive surgical intervention (4).

Guided bone regeneration (GBR) is an established technique in oral maxillofacial reconstructive surgery to regenerate the cancellous bone of the maxilla and mandible $(5,6)$. In GBR, bone substitute is used to fill the defect, which is then overlaid by a barrier membrane. The latter creates a favorable microenvironment for repopulation of osteoprogenitor cells into bone substitute to guide bone repair and prevent non-osseous tissue ingrowth from the gingiva (7). Ideal membranes for GBR are osteoconductive, in that they are able to directly stimulate the growth of osseous cells (8), promote vascularization of the healing tissue to fulfil tissue diffusion requirements and promote osseous regeneration (9). While several synthetic materials have been used for GBR, bio-resorbable scaffolds are favored as it negates the need for postoperative retrieval. Theoretically, GBR may enhance bone regeneration in orthopedic applications, but the use of GBR for this purpose has been limited by the lack of an ideal barrier membrane that able to support bridging of cortical bone with minimal interference in the repair process. 
Bioactive membranes derived from collagen are a popular choice in tissue engineering applications. Collagens are the most abundant extracellular matrix (ECM) proteins (10), with low immunogenicity, and inherent bioactivity and biodegradability. The porous structure of a collagen-derived barrier membrane may also be ideal to facilitate tissue ingrowth and hence efficient bone formation (11). Despite many attempts, poor mechanical properties, as well as local toxicity from remnants of crosslinking chemicals such as glutaraldehyde,(12) has hindered the application of collagen-based GBR membranes in orthopedics. Previously, we used a new collagen membrane, CelGro ${ }^{\mathrm{TM}}$, in the repair of a cortical bone defect in a rat model. CelGro $^{\mathrm{TM}}$ was shown to facilitate bridging the gap of a cortical bone defect (13) and improve vascularization(14). The induction of cortical bone regeneration was evaluated using a combination of CelGro ${ }^{\mathrm{TM}}$ and recombinant human bone morphogenic protein-2 (BMP-2), which was found to significantly improve repair of both cancellous and cortical metaphyseal defects (13). Since CelGro ${ }^{\mathrm{TM}}$ has been shown to induce cellular recruitment, upregulate proosteogenic factors at the implant site(15) (16) and promote vascularization (17), we hypothesized that $\mathrm{CelGro}^{\mathrm{TM}}$ alone, without growth factors such as BMP-2, is able to directly participate in repair of cortical defects through osseointegration property.

In this study, we evaluated the physical characteristics of CelGro ${ }^{\mathrm{TM}}$, and determined its efficacy as a bioactive barrier membrane for GBR in a rabbit model of cortical bone regeneration and in a human clinical study for the treatment of periodontal bone defects around dental implants.

\section{Materials and Methods}

\subsection{Biomaterials}


$\mathrm{CelGro}^{\mathrm{TM}}$ is a porcine-derived collagen membrane developed at the University of Western Australia $(18,19)$ and manufactured in Australia by Orthocell Ltd. Porcine connective tissue was defatted, followed by denaturing of non-collagenous proteins using $1 \%(\mathrm{v} / \mathrm{v})$ sodium dodecyl sulphate and $0.5 \%(\mathrm{v} / \mathrm{v}) \mathrm{LiCl}$ at $4^{\circ} \mathrm{C}$ overnight. This was followed by further processing of the tissue in $0.5 \%(\mathrm{v} / \mathrm{v}) \mathrm{HCl}$ to denature the collagen, then neutralizing with $0.5 \%$ $(\mathrm{v} / \mathrm{v}) \mathrm{NaOH}$ solution. The tissue was subjected to mechanical stretching to reach the desired size and thickness before further denaturation in a solution of $1 \%(\mathrm{v} / \mathrm{v}) \mathrm{HCl}$ solution for 24 hours.

Bio-Gide ${ }^{\circledR}$ (Geistlich Pharma) is a porcine-derived collagen membrane used previously for GBR and thus was used as for comparison. It has been shown that Bio-Gide ${ }^{\circledR}$ is composed of Type I and III collagen and has a bilayer structure. The collagen fibrils are not crosslinked or modified from their native structure (20).

\subsection{Characterization}

Initially, structural morphology of CelGro ${ }^{\mathrm{TM}}$ was characterized by scanning electron microscopy (SEM; Supra 55, Zeiss), micro-computed tomography (micro-CT; Xradia 520, Zeiss) and transmission electron microscopy (TEM; JEM 2100, Jeol) at the Centre for Microscopy, Characterisation and Analysis, University of Western Australia. Protein composition of CelGro ${ }^{\mathrm{TM}}$ was determined by Western blot and immunohistochemistry. The presence of residual cells and galactose-alpha-1,3-galactose ( $\alpha$-gal) on the membranes was investigated by confocal laser scanning microscopy (CLSM) (Nikon A1, Nikon).

Physical characteristics of CelGro ${ }^{\mathrm{TM}}$ and Bio-Gide ${ }^{\circledR}$ were compared, assessing structural morphology, physico-chemical properties and mechanical strength. To assess structural 
morphology, membranes were fixed in paraformaldehyde (4\%) and embedded in paraffin. Sections (4-6 $\mu \mathrm{m})$ were cut and transferred onto glass slides, dewaxed, and stained with Goldner's Trichrome and examined by light microscopy, or evaluated by SEM (Leica Cambridge S260) with measurements of pore size and collagen bundle diameter on the different sides. Physicochemical testing included $\mathrm{pH}$, thickness, water retention and mechanical strength of each membrane. Membranes (10x10 mm) were immersed in $2 \mathrm{ml} 0.9 \%$ $\mathrm{NaCl}$ at room temperature for 20 minutes. The $\mathrm{pH}$ of the immersion fluid was measured using a Horiba LAQUA twin compact hand-held $\mathrm{pH}$ meter after equilibration. Thickness and water retention capacity was performed using the method described by Pallela et al (21). Dry thickness of each article was measured using a calibrated THO1 electronic thickness gauge. Water retention of the test articles at equilibrium (ER) was calculated by weighing the materials while dry $\left(W_{d r y}\right)$ and immediately after immersion in $0.9 \% \mathrm{NaCl}$ solution $\left(W_{\text {wet }}\right)$ and centrifugation to remove unbound moisture. The following equation was used to calculate water retention capacity:

$$
E R=\left[\frac{W w e t-W d r y}{W d r y}\right] X 100
$$

Mechanical strength was measured by evaluating the force required to tear the membrane. Each article was cut into three $3 \mathrm{cmx} 0.5 \mathrm{~cm}$ samples, immersed in $0.9 \% \mathrm{NaCl}$ and equilibrated at room temperature for 90 minutes. After draining excess moisture, the thickness of the membrane was measured at the top, middle, and bottom of the sample using an electronic thickness gauge. Testing grips were attached to the opposing $0.5 \mathrm{~cm}$ sides of each test article strip and loaded into the Instron mechanical testing system (Model5566, Instron). The test 
article strips were pre-loaded with $0.1 \mathrm{~N}$ and force loading was increased at a speed of $2 \mathrm{~mm} / \mathrm{sec}$ until failure at the centre of the membrane was reached. Ultimate tensile strength was calculated as failure force divided by the area of the testing material $(\sim 30 \mathrm{~mm} \times 5 \mathrm{~mm})$.

\subsection{Animal study}

To examine the performance of collagen membranes in cortical bone regeneration, CelGro ${ }^{\mathrm{TM}}$ was evaluated in a rabbit diaphyseal defect model. Bio-Gide ${ }^{\circledR}$ was used as a comparison membrane for cortical bone regeneration in the model. The protocol was modified from a previously published method (22) (23) in which the defect was created in the metaphysis. The study was performed on 28 skeletally mature, male, New Zealand white rabbits weighing 2.5-3 $\mathrm{kg}$. The animals were randomly assigned to one of five treatment groups: no treatment (NT;

$n=3)$, defect only (D; $n=7)$, autograft only (AG; $n=6)$, autograft plus Bio-Gide ${ }^{\circledR}(A G+B ; n=6)$, and autograft plus CelGro ${ }^{\mathrm{TM}}(\mathrm{AG}+\mathrm{C} ; \mathrm{n}=6$ - see Fig. S1). Animal care and maintenances was conducted according to the Australian National Health and Medical Research Council (NHMRC) guidelines and experimental protocols were approved by the Ethics Committees of Kunming Medical University (Approval No. SCXK (DIAN) K2015-0004). Autogenous iliac trabecular bone grafts (approximately $0.4 \mathrm{~cm}^{3}$ volume) were harvested from the right ilium, which was exposed via incision at the crista iliaca, using haemostatic forceps. Bone autograft was harvested for $\mathrm{AG}, \mathrm{AG}+\mathrm{B}$ and $\mathrm{AG}+\mathrm{C}$ groups. The cortical bone in the diaphysis region of right distal femur was then exposed through a longitudinal medial parapatellar incision. A defect of $5 \mathrm{~mm}$ in diameter, $5 \mathrm{~mm}$ in depth, and $2 \mathrm{~mm}$ from the linea epiphysialis, was created in the cortical bone diaphysis of the right femur (in groups $\mathrm{D}, \mathrm{AG}, \mathrm{AG}+\mathrm{B}, \mathrm{AG}+\mathrm{C}$ ). Harvested trabecular bone graft was implanted into the bone defect site (in groups $A G, A G+B, A G+C$ ). 
For treatment groups receiving a collagen membrane $(\mathrm{AG}+\mathrm{B}$ and $\mathrm{AG}+\mathrm{C})$, a pre-sterilized circular piece of membrane (CelGro ${ }^{\mathrm{TM}}$ or Bio-Gide $\left.{ }^{\circledR}\right)$, measuring $5 \mathrm{~mm}$ in diameter, was saturated in PBS and placed over the defect site with the rough side facing the bone interface. Gentle pressure was applied to the membrane to smooth the edge over the bone defect site. For all surgical groups, the incision over the defect site was then sutured closed.

All animals received antibiotic prophylaxis (Cefazolin, $10 \mathrm{mg} / \mathrm{kg}$ ) administered intramuscularly once daily for three days post-operatively. Sacrifice via pentobarbital overdose occurred 30 days and 60 days post-operatively (Fig S1), except for animals in the no treatment group, which were sacrificed at 60 days only.

To visualize and evaluate cortical bone defect healing in different groups, the area around the bone defect and normal cortical bone were scanned by micro-CT (Skyscan1176, Bruker) at 80 $\mathrm{keV}, 313 \mu \mathrm{A}$, isotropic resolution $8.89 \mu \mathrm{m}$, followed by reconstruction (NRecon, Bruker). The volume of interest (VOI) was precisely defined as $6 \mathrm{~mm} \times 5 \mathrm{~mm}$ at the defect site (lateral) and on the normal cortical bone (medial) by CTANalyser (Bruker). The volume of bone tissue (BV) and porosity volume (Po.V) were expressed as a fraction of the selected total volume (TV). Normalized cortical thickness ( $\Delta \mathrm{Ct}$.Th) was calculated by the absolute value between the cortical thickness of the defect and normal bone tissue.

To determine the correlation between radiologic findings and histologic changes of the bone tissue at the cortical bone defect, histological examination was conducted on samples harvested 60 days postoperatively. Fixed bone samples were dehydrated in increasing concentrations of ethanol and defatted in three changes of xylene prior to infiltration, which was carried out at $4^{\circ} \mathrm{C}$ under vacuum in methyl methacrylate (MMA) infiltration mixture (98\% MMA, 10\% 
Dibutyl Phthalate and 1\% Perkadox16). Samples were placed in a Teflon mold containing the infiltration solution with $0.01 \%$ accelerator. Polymerization occurred in an airtight water bath at $25-29^{\circ} \mathrm{C}$ overnight. The polymerized blocks were mounted onto a universal holder using HistoResin mounting medium and trimmed prior to sectioning. Sections $(5 \mu \mathrm{m})$ were collected on silane-coated slides, covered with Kisoil Foil, pressed using a section mounting press and left at $37^{\circ} \mathrm{C}$ for $2-3$ days. The resin was removed from the section prior to staining. Sections were stained with Goldner's Trichrome according to standard protocols(24) and analyzed microscopically (Aperio Scanscope, Leica).

\subsection{Proof of concept human study}

GBR is a standard procedure used routinely in clinical practice to preserve and restore bone volume in oral maxillofacial reconstructive surgery. To support the clinical translation of $\mathrm{CelGro}^{\mathrm{TM}}$ in GBR, a clinical trial was conducted to evaluate the performance of $\mathrm{CelGro}^{\mathrm{TM}}$ and its use in GBR for dental implant procedures. Participant characteristics, inclusion/exclusion criteria and study details are provided in the Supplementary Information. The study was conducted in compliance with the Declaration of Helsinki and ICH/GCP and was registered at ANZCTR (trial ID ACTRN12615000027516). All participants enrolled in this study provided written, informed consent and the study protocol was approved by the St John of God Health Care Human Research Ethics Committeeon February 112015.

A two-stage dental implant procedure was used for this study. The surgical procedures associated with GBR have been described elsewhere(25). In brief, following standard oral premedication and anesthesia, the implant site was prepared, removing all soft tissue remnants from the bone surface. An appropriately-sized screw-type titanium implant was placed into the 
alveolar bone of the mandible or maxilla using standard procedures. Void-filling material (BioOss $^{\circledR}$, Geistlich Pharma) was prepared and packed into the bone defect. CelGro ${ }^{\mathrm{TM}}$ was cut to size and placed in situ with the rough side facing the void-filling material and held in place with moderate pressure until adhesion to the site was achieved. The gingiva was sutured closed over the implant and patients received instructions for post-operative care (antiseptic mouthwash), antibiotics and analgesics as required according to standard protocols (26). Re-entry surgery to anchor the implant abutment conducted 4-6 months post-operatively to allow sufficient time for implant osseointegration . Cover screws were replaced by healing abutments and the mucoperiosteal flaps were adjusted to fit around the neck of the healing abutment before being sutured in place.

Cone Beam Computed Tomography (CBCT) was used to analyze the quality and volume of new tissue formation immediately after implant placement (baseline) and prior to re-entry surgery. The measured parameters included; the distance from the implant shoulder to the implant contact (DIB), measurement of the alveolar crest relative to the point at which the implant was embedded in the bone (CREST measurement) and the horizontal thickness of the buccal alveolar crest measured at $1 \mathrm{~mm}$ (HT1), $3 \mathrm{~mm}$ (HT3) and 5mm (HT5) below the implant shoulder. Visual assessment of bone regeneration was conducted at the time of re-entry surgery according to methods described in Annen (27) and Becker (25) using QT score. A QT score of 5 indicates corticalization of newly formed bone with integration and consolidation of voidfilling materials. Mucoperiosteal flaps were reflected for evaluation of the remaining defect dimensions.

Potential complications and adverse events related to the use of CelGro ${ }^{\mathrm{TM}}$ were also collected, including site specific reactions such as pain (unidirectional numeric rating scale - NRS), tissue 
condition (uneventful, inflammation, swelling, fibrin, plaque, necrosis) and soft tissue dehiscence, as well as systemic reactions.

\subsection{Statistical methods}

Data is presented as mean \pm standard deviation unless otherwise stated. Due to the small sample size, micro-CT data from the rabbit femur cortical bone defect model was compared between two groups using a t-test. Statistical analysis, consisting of one-way analysis of variance (ANOVA), was performed on the clinical study CBCT data at baseline and re-entry surgery. All statistical analyses were carried out using SPSS software (v 24.0; IBM Corp, USA). P $<0.05$ was considered as significantly different.

\section{Results}

\subsection{Characterization of CelGro ${ }^{\mathrm{TM}}$ collagen membrane}

We first investigated topographical characteristics of CelGro ${ }^{\mathrm{TM}}$ to understand the structural configuration of the membrane. As observed by the SEM and micro-CT images (Fig.1A-E), CelGro $^{\text {TM }}$ has a bilayer structure consisting of a smooth side (Fig. 1B, D) of densely aligned collagen bundles, and a rough side of randomly distributed collagen bundles that form a porous matrix (Fig. 1C, E). TEM results show the periodicity of CelGro ${ }^{\mathrm{TM}}$ collagen fibers range from 55 to $57 \mathrm{~nm}$, and the diameters range between 80 to $100 \mathrm{~nm}$ (Fig.1F, G).Immunohistochemistry showed that type I collagen staining was evident across the entire membrane (Fig $1 \mathrm{H})$, but no type III collagen staining was detected (Fig S4). Western blot analysis showed high levels of collagen I proteins, including type $\gamma$, type $\beta$ and type $\alpha$, in CelGro ${ }^{\mathrm{TM}}$ membrane lysate (Fig. 1I). These results indicate that CelGro ${ }^{\mathrm{TM}}$ is composed almost exclusively of Type I collagen. 
While collagen-based scaffolds may be ideal for various tissue engineering applications(28), co-contaminating non-collagen molecules and residual impurities of chemical processing may cause adverse biological reactions. For example, $\alpha$-gal, which is commonly found in porcine tissue-derived biomaterials, may cause severe anaphylactic reactions in susceptible humans(29). To further examine the purity of CelGro ${ }^{\mathrm{TM}}$, we performed immunohistochemistry to evaluate the level of $\alpha$-gal. CLSM images (Fig.1J) confirm that CelGro ${ }^{\mathrm{TM}}$ contains no cellular components and has no detectable levels of $\alpha$-gal, evidenced by no fluorescence detected on both DAPI-stained and isolectin/GS-IB4-stained images respectively.

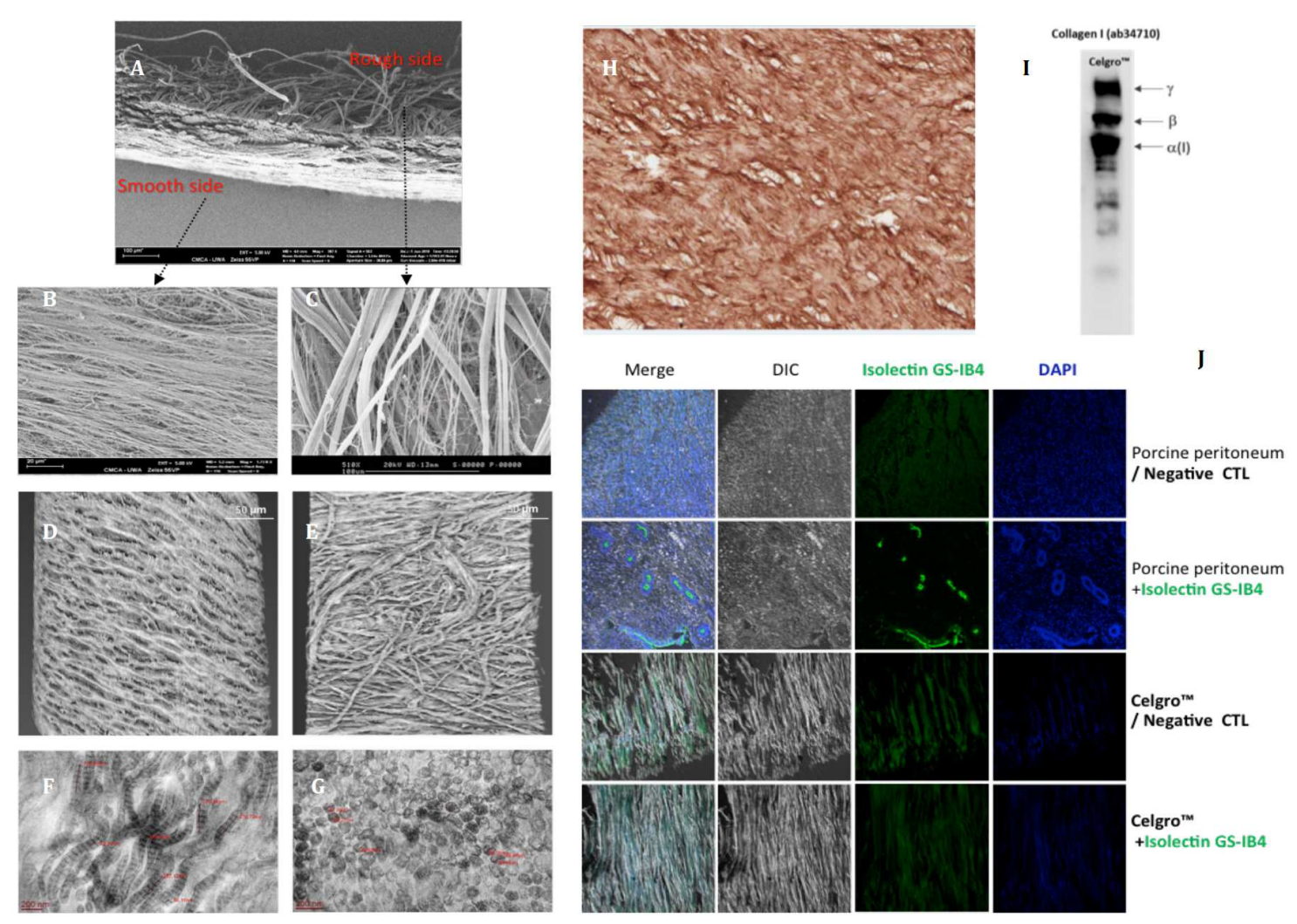

Figure 1: Characterizations of CelGro ${ }^{\mathrm{TM}}$ membrane. 
(A) Cross-sectional view of CelGro ${ }^{\mathrm{TM}}$ with tightly packed smooth side on the bottom and rough side on the top using low magnification SEM imaging. (B, C) The surface morphology of CelGro ${ }^{\mathrm{TM}}$ showing the structure of the smooth side and rough side at high magnification using SEM. (D, E) Potassium iodine-based contrast enhanced micro-CT images of the smooth side and rough side of CelGro ${ }^{\mathrm{TM}}$; (F) TEM image of longitudinal view of CelGro ${ }^{\mathrm{TM}}$ with measurement of the length of the tropocollagen constituents using TEM. (G) TEM image of sectional view of CelGro ${ }^{\mathrm{TM}}$ with the measurement of the diameter of the collagen fibers. $(\mathrm{H})$ Immunohistochemistry staining of CelGro ${ }^{\mathrm{TM}}$ showing predominance of Type I collagen (stained brown) (I) Western blot of Type I collagen protein extracted from CelGro ${ }^{\mathrm{TM}}$. (J) CLSM showing comparison between the unprocessed porcine peritoneum and CelGro ${ }^{\mathrm{TM}}$. Alpha-gal is labelled with Isolectin GS-IB4 and the cell nucleus is labelled with DAPI.

We then compared the physical characteristics of $\mathrm{CelGro}^{\mathrm{TM}}$ with a commercially available collagen membrane, Bio-Gide ${ }^{\circledR}$ (30). Histology and SEM results (Figure 2 A-F) showed that

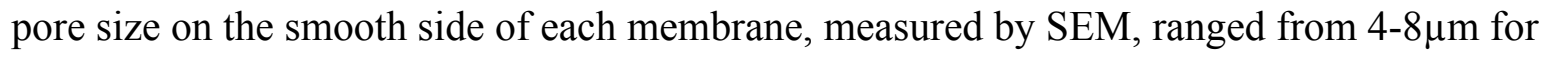
Bio-Gide ${ }^{\circledR}$ and 3-7 $\mu \mathrm{m}$ for CelGro ${ }^{\mathrm{TM}}$. As the average human fibroblast measures approximately $50-100 \mu \mathrm{m}$ in diameter $(31,32)$, the pore size of both CelGro ${ }^{\mathrm{TM}}$ and Bio-Gide ${ }^{\circledR}$ is sufficient to prevent migration of epithelial cells across the scaffolds in vivo. The collagen bundles on the

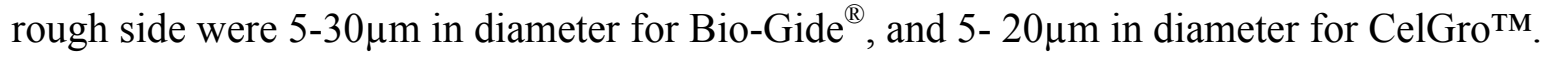
The gap between the collagen bundles, which is used to estimate the pore size on the rough side ranged from $44-171 \mu \mathrm{m}$ for Bio-Gide ${ }^{\circledR}$, and $75-142 \mu \mathrm{m}$ for CelGro ${ }^{\mathrm{TM}}$ (Table 1). CelGro ${ }^{\mathrm{TM}}$ exhibited greater uniformity in arrangement of collagen bundles, and the surface of the bundles was smoother compared to those observed for Bio-Gide ${ }^{\circledR}$ (Figure 2 C-D). 
Change in $\mathrm{pH}$ can significantly affect cell function, and even cause tissue injury (33). The $\mathrm{pH}$ values of the saline extract for both materials (Table 1) are close to the $\mathrm{pH}$ value of commercial saline (around $\mathrm{pH}$ 5.5), which is safe in vivo due to the buffering effect of body fluid (34). The presence of CelGro ${ }^{\mathrm{TM}}$ had little effect on the $\mathrm{pH}$ value of the saline solution, while Bio-Gide ${ }^{\circledR}$ slightly alkalized the solution.

Moderate wettability promotes high levels of cell adhesion to scaffolds (35). We measured the change to thickness and mass of $\mathrm{CelGro}^{\mathrm{TM}}$ and Bio-Gide ${ }^{\circledR}$ after wetting. CelGro ${ }^{\mathrm{TM}}$ had less variation in shape and thickness in both dry and wet conditions compared to Bio-Gide ${ }^{\circledR}$. $\mathrm{CelGro}^{\mathrm{TM}}$ showed less deformation than Bio-Gide ${ }^{\circledR}$ after wetting due to straighter alignment of collagen bundles in CelGro ${ }^{\mathrm{TM}}$, as seen in SEM, compared to Bio-Gide ${ }^{\circledR}$. However, there was no significant difference between two scaffolds in hydrophilicity, as water retention rates were very similar (Table 1).

Mechanical strength (ultimate tensile strength and failure force) of the two scaffolds was also tested. CelGro ${ }^{\mathrm{TM}}$ had a slightly higher failure force and, due to its thinner cross-sectional diameter, a slightly higher ultimate tensile strength. (Table 1) 
CelGro $^{\mathrm{TM}}$
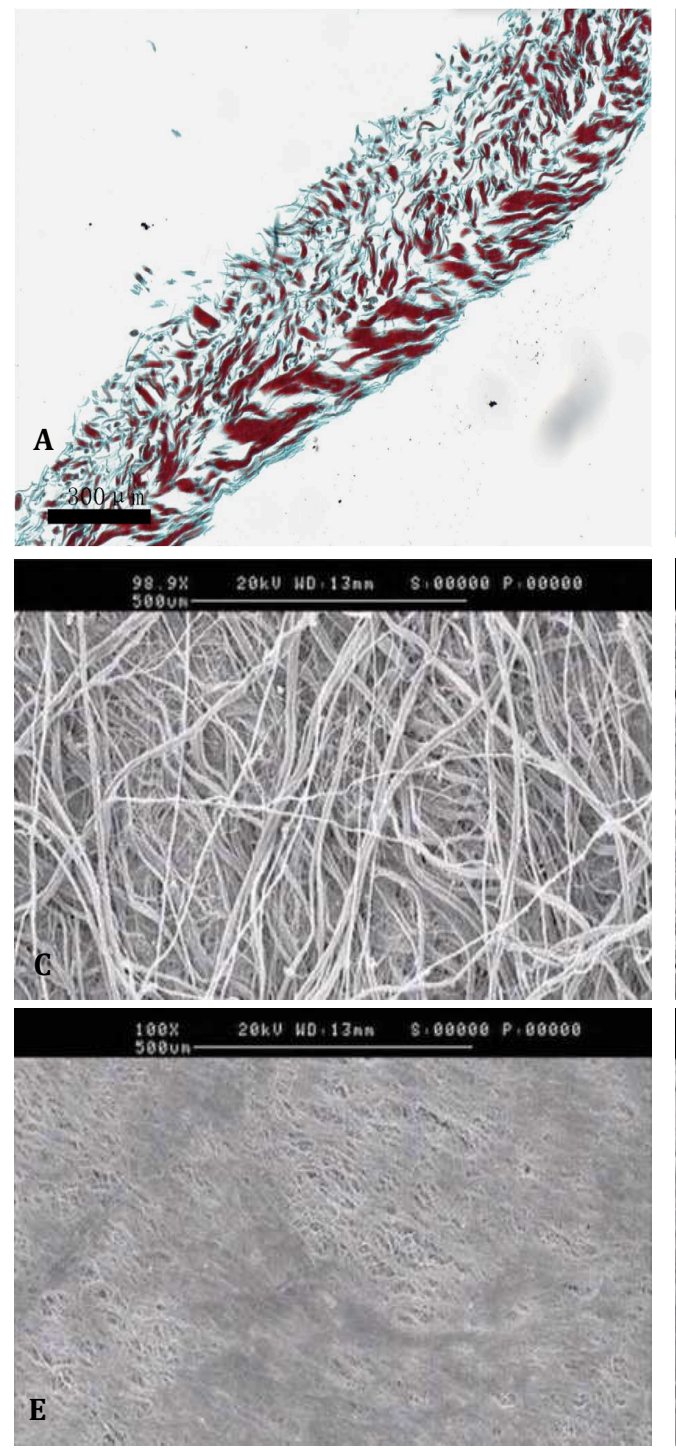

Bio-Gide ${ }^{\circledR}$
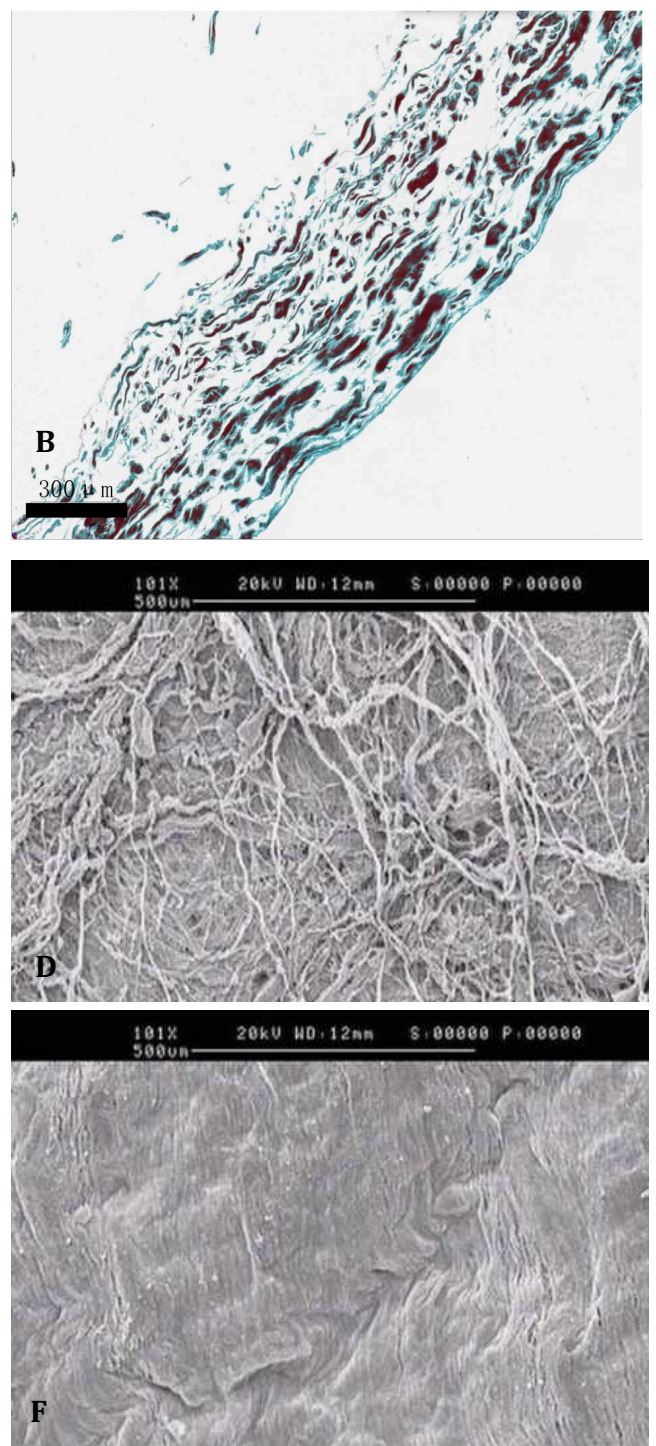

Figure 2: Comparative studies on the morphology of CelGro ${ }^{\mathrm{TM}}$ and Bio-Gide ${ }^{\circledR}$. Histological morphology of a cross-section of CelGro ${ }^{\mathrm{TM}}(\mathrm{A})$ and Bio-Gide ${ }^{\circledR}(\mathrm{B})$. SEM image of the rough side of CelGro ${ }^{\mathrm{TM}}(\mathrm{C})$ and Bio-Gide ${ }^{\circledR}(\mathrm{D})$. SEM image of the smooth side of CelGro ${ }^{\mathrm{TM}}(\mathrm{E})$ and Bio-Gide $^{\circledR}(\mathrm{F})$ 


\begin{tabular}{|c|c|c|}
\hline & CelGro $^{\mathrm{TM}}$ & Bio-Gide $^{(B}$ \\
\hline Pore size range on the smooth side $(\mu \mathrm{m})$ & $4.6 \pm 1.8(3-7)$ & $5.0 \pm 2.3(4-8)$ \\
\hline $\begin{array}{l}\text { Collagen bundle diameters on the rough side } \\
(\mu \mathrm{m})\end{array}$ & $11.0 \pm 3.8(5-20)$ & $14.1 \pm 5.8(5-30)$ \\
\hline Pore size range on the rough side $(\mu \mathrm{m})$ & $95 \pm 31(75-142)$ & $86 \pm 38(44-171)$ \\
\hline Dry Thickness $(\mu \mathrm{m})$ & $358 \pm 87(253-511)$ & $483 \pm 91(384-630)$ \\
\hline Wet Thickness $(\mu \mathrm{m})$ & $311 \pm 48(264-395)$ & $376 \pm 63(297-500)$ \\
\hline Water Retention Capacity (\%) & $478 \pm 26(449-500)$ & $533 \pm 14(517-544)$ \\
\hline $\mathrm{pH}$ & $5.5 \pm 0.06(5.4-5.5)$ & $6.7 \pm 0.2(6.5-6.9)$ \\
\hline Failure Force $(\mathrm{N})$ & $5.4 \pm 0.38(5.01-5.76)$ & $2.99 \pm 0.33(2.61-3.23)$ \\
\hline Ultimate Tensile Strength (MPa) & $0.35 \pm 0.06(0.27-0.40)$ & $0.16 \pm 0.03(0.12-0.19)$ \\
\hline
\end{tabular}

\subsection{Regeneration of cortical bone defects in a rabbit model}

While the in vitro characterisation of $\mathrm{CelGro}^{\mathrm{TM}}$ showed that $\mathrm{CelGro}^{\mathrm{TM}}$ contains relatively pure type I collagen bundles and display less deformity and better mechanical strength, we next conducted a preclinical study to determine the efficacy of CelGro ${ }^{\mathrm{TM}}$ for GBR in the repair of diaphysis cortical bones defects in rabbits. Previously, it has been shown that healing of a standard-sized defect in rabbit femoral bone treated with bone autograft occurs between 30 to 60 days after surgery (22) (23). To evaluate the efficacy of collagen membranes in conjunction 
with a bone autograft in cortical bone repair in rabbit, we selected 30 and 60 days' time points for examination of cortical bone restoration.

At 30 days after surgery, the effect of a collagen membrane could be clearly observed by micro-CT (Fig. 3A). In both GBR groups $(\mathrm{AG}+\mathrm{B} / \mathrm{AG}+\mathrm{C})$, the regenerated bone had formed a continuous cortex over the defect area; the defects were completely sealed by the neo-cortex in 3D reconstruction views. In the autograft only group (AG), although new bone tissue was present in the defect site, the defect had not been completely sealed by new bone growth. In animals where the defect was left untreated (no bone autograft or collagen membrane (defect only group D), the defect was largely unsealed (Fig 3A). The significantly higher BV/TV observed in the $\mathrm{AG}+\mathrm{C}, \mathrm{AG}+\mathrm{B}$ and $\mathrm{AG}$ groups (Fig. $3 \mathrm{C} ; \mathrm{P}<0.05$ ), compared to the defect only group (D), was due to the induction of bone formation by autogenous bone graft.

At 60 days after surgery, lower Po.V/TV and increased BV/TV (Fig. 3C) were observed in the $\mathrm{AG}+\mathrm{B}$ and $\mathrm{AG}+\mathrm{C}$ treatment groups compared to the $\mathrm{AG}$ group and $\mathrm{D}$ group $(\mathrm{P}<0.05)$, and the regenerated bone cortex formed in the treatment groups with a collagen membrane $(\mathrm{AG}+\mathrm{B} / \mathrm{AG}+\mathrm{C})$ also showed significantly lower $\Delta \mathrm{Ct}$.Th $(\mathrm{P}<0.05)$ (Fig 3C). Together, the micro-CT data indicates that, compared to the treatment groups without a collagen membrane, use of a collagen membrane resulted in increased bone volume and a more mature cortex. Dense, firm mineral precipitation with a similar shape and density to adjacent healthy cortical bone was observed by micro-CT (Fig. 3B) in the $A G+B$ and $A G+C$ treatment groups. Nearnormal corticalization of cortical bone defects in the CelGro ${ }^{\mathrm{TM}}$ group $(\mathrm{AG}+\mathrm{C})$ was seen at 60 days, while a slight irregularity remained in the Bio-Gide ${ }^{\circledR}$ group $(A G+B)$ in sagittal and crosssectional imaging (Fig 3B). The micro-CT data was congruent with histological appearance in 
all groups. The cortical defect area was filled by linear neo-cortex surrounded with visible osteoid tissue, indicating highly active bone formation. The newly-formed cortical bone complete bridged the defect, and partially absorbed trabecular bone graft was found in the medullary compartment. CelGro ${ }^{\mathrm{TM}}$ showed improved cortical alignment and reduced porosity at the defect interface as compared to Bio-Gide ${ }^{\circledR}$ (Fig 3D). 


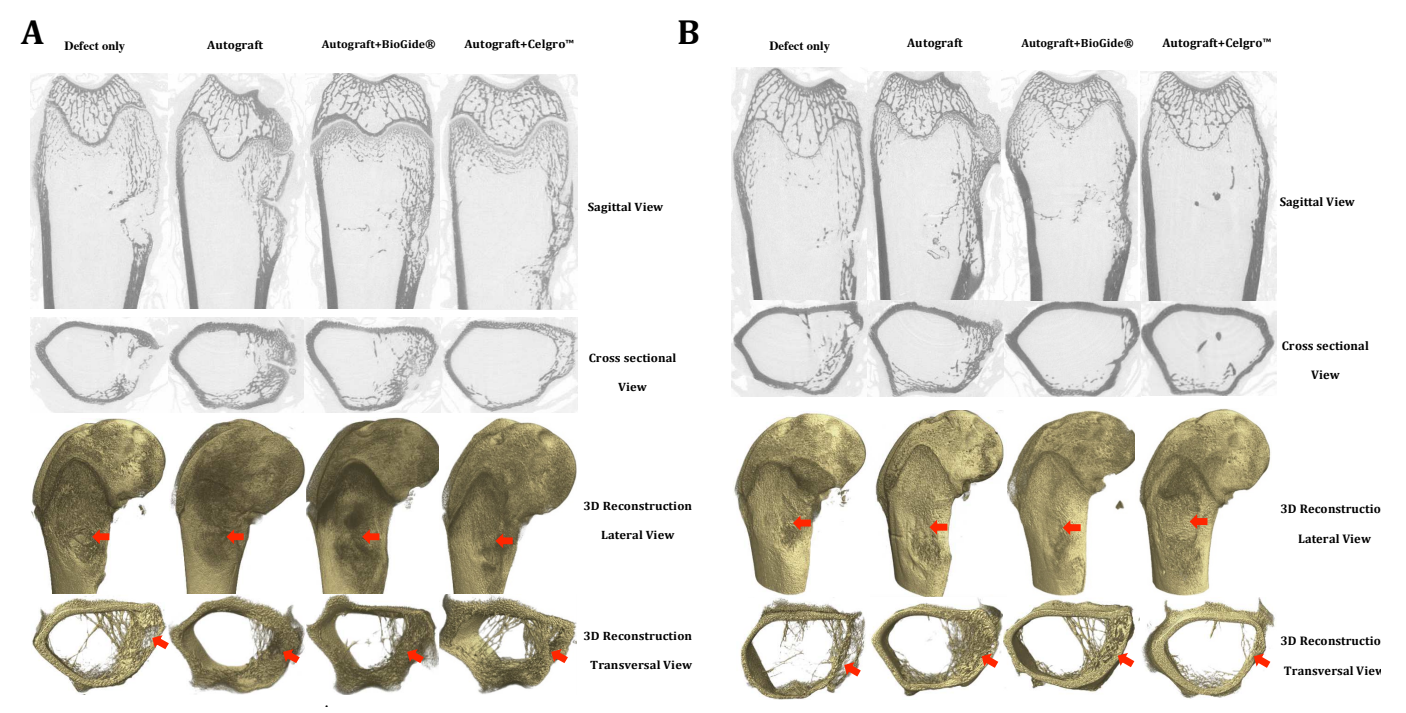

C

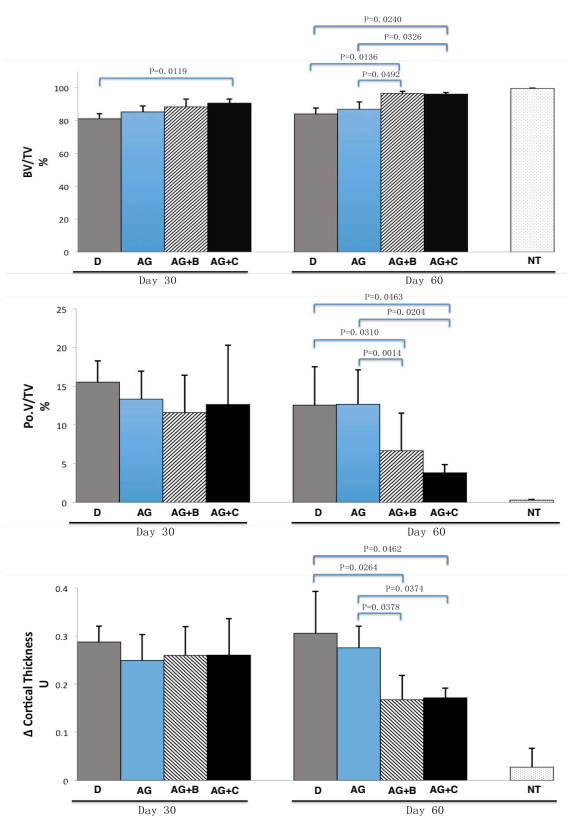

D

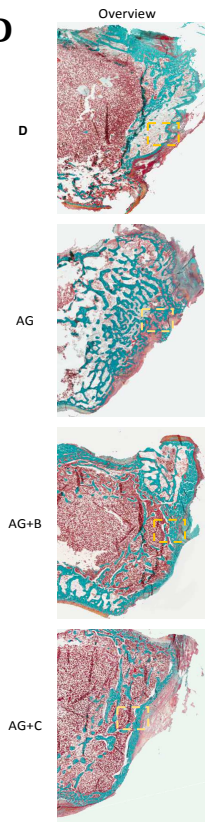

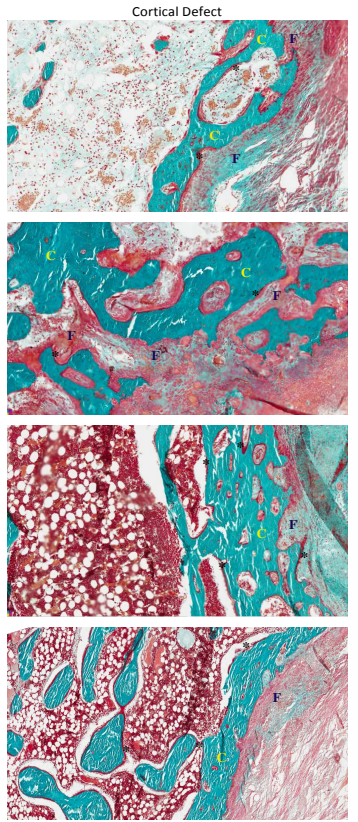


Figure 3: Preclinical evaluation of the GBR performance in rabbit femoral cortical bone.

(A) Representative micro-CT images of the femur defect at 30 days after surgery. (B) Representative micro-CT images of the femur defect at 60 days after surgery. (C) Micro-CT data of the femur defect model comparing different treatment groups at 30 and 60 days after surgery. (D) Representative histology of the femoral defect showing bone formation in the specimens belonging to groups after 60 days at low and high magnification. Legend: The red arrows indicate the cortical bone defect area. Yellow ' $\mathrm{C}$ ' indicates newly formed cortex; Purple ' $\mathrm{F}$ ' indicates fibrous tissue; * indicates osteoid tissue.

\subsection{Proof of concept clinical study of CelGrot ${ }^{\mathrm{TM}}$ in GBR}

The promising pre-clinical data of cortical bone restoration in diaphyseal cortical bones defects of rabbits has promoted us to translate the study into the proof of concept clinical study in human. Owning the fact that selection of orthopedic patients with cortical bone defects is complex and since GBR is an established, commonly-used technique in dental implant procedures, we selected dental GBR for provide evidence for the clinical translation of CelGro ${ }^{\mathrm{TM}}$ in humans.

Ten participants received GBR using CelGro ${ }^{\mathrm{TM}}$ around 16 dental implants in a 2-stage clinical

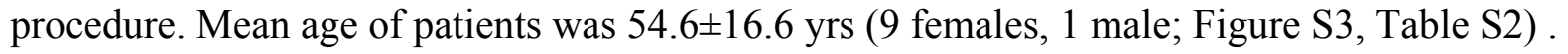
No device-related adverse outcomes, such as abnormal post-operative pain (Figure S5) or wound infection were observed. Tissue conditions such as swelling and inflammation were generally mild and transient in nature, and did not affect treatment outcomes. One incidence of wound dehiscence was noted but the participant did not require intervention and no effect on bone regeneration was noted.

CBCT (36) was used to measure bone regeneration at treatment sites. DIB was significantly lower at re-entry surgery $(\mathrm{p}=0.015)$ than at implant placement (baseline), indicating 
regeneration of bone towards the implant shoulder. Alveolar crest height was preserved (no bone resorption) and facial bone wall thickness was maintained between baseline and at reentry $(p=0.168)$, indicating that GBR treatment with $\mathrm{CelGro}^{\mathrm{TM}}{ }^{\mathrm{m}}$ was associated with preservation of bone volume post-implant. Buccal alveolar crest thickness measurements indicated that horizontal thickness of the alveolar bone was significantly increased at the deeper apical levels, $3 \mathrm{~mm}(\mathrm{p}=0.001)$ and $5 \mathrm{~mm}(\mathrm{p}=0.004)$ from the implant shoulder, suggesting that GBR was successfully achieved in the horizontal dimension. The mean QT score for all implant sites treated with CelGro ${ }^{\mathrm{TM}}$ was $4.56 \pm 0.63$ (of a possible maximum score of 5), indicating integration of void filling material into new mature bone. All treatment sites demonstrated sufficient regenerated bone to proceed to placement of the healing abutment, and subsequently crown placement and force loading. 

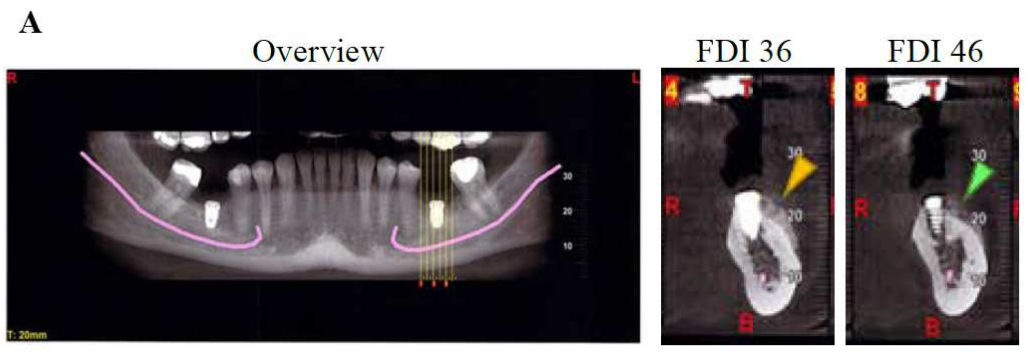

Post-implant

(Visit 2)
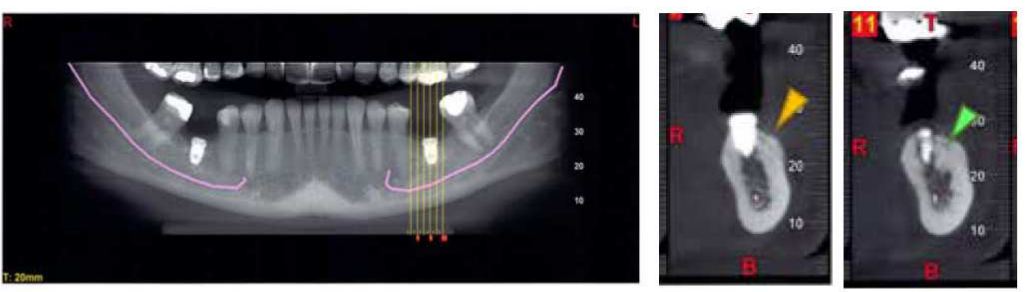

Before Re-entry Surgery

(Visit 4)
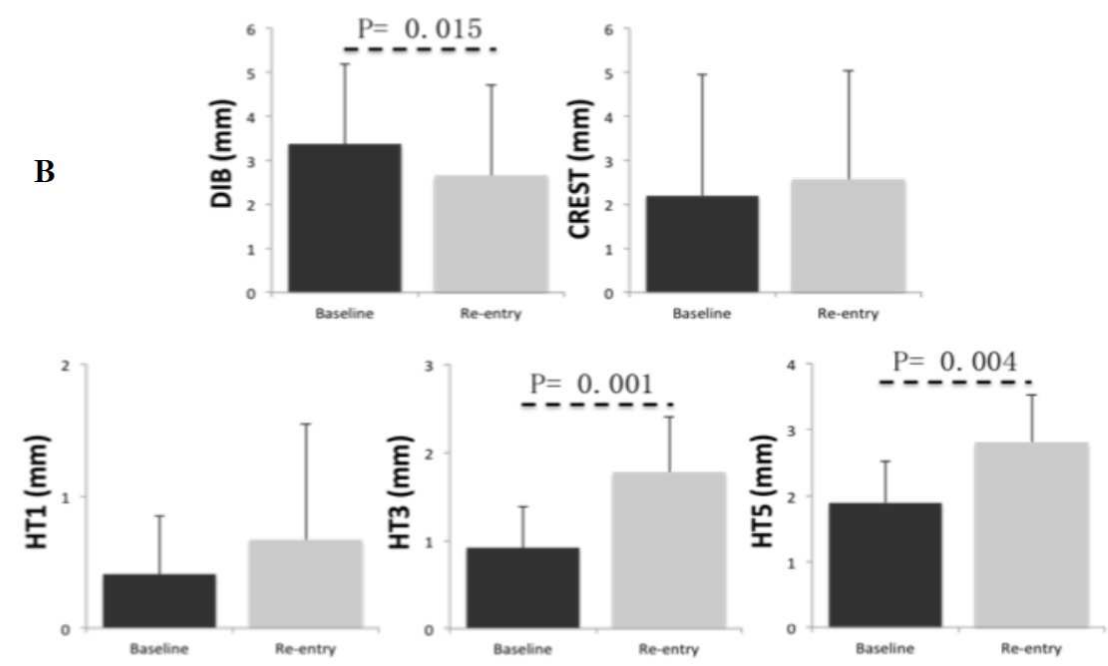

Figure 4: CBCT results of human proof of concept case series study. (A) Representative CBCT images demonstrating guided bone regeneration at post-treatment time-points of 12 days post-implant (Visit 2) and 6 months (Visit 4). (B) Vertical and horizontal measurements from $\mathrm{CBCT}$ of bone regeneration before and after GBR with CelGro ${ }^{\mathrm{TM}}$. Legend: Yellow arrowheads represent the bone graft material implant site at Fédération Dentair Internationale (FDI) site 36; Green arrowheads represent the bone graft material implant site at FDI site 46. 


\subsection{Discussion}

The use of GBR to restore bone volume began in maxillofacial reconstruction. The advantage of barrier membranes in GBR is to prevent soft tissue ingrowth during bone regeneration. Little evidence exists as to whether a barrier membrane can be used to guide cortical bone formation in large defects that do not heal adequately. We have developed CelGro ${ }^{\mathrm{TM}}$, a noncross-linked type I collagen-based membrane that can be used to simulate the ECM of bone for bone regeneration. The characterization of $\mathrm{CelGro}^{\mathrm{TM}}$ show that it is acellular and does not retain any trace of a major cellular xenoantigen, $\alpha$-gal. CelGro $^{\mathrm{TM}}$ display less deformity and better mechanical strength compared to Bio-Gide ${ }^{\circledR}$. In an in vivo study of a cortical bone defect in the rabbit, CelGro ${ }^{\mathrm{TM}}$ augmented bridging of the gap of a cortical bone defect and directly participated in repair of cortical defects. It appears that improvement of cortical alignment and reduced porosity at the defect interface is greater in CelGro ${ }^{\mathrm{TM}}$ than that in Bio-Gide ${ }^{\circledR}$.

The characteristics of an open, porous structure ('rough') on one side and dense, compact structure ('smooth') on other side of CelGro ${ }^{\mathrm{TM}}$ is a unique property for tissue regeneration. The collagen fibers on the 'smooth' side have an organized alignment which may act as a barrier to prevent non-osseous tissue ingrowth. Pore size on the smooth side was 3-7 $\mu \mathrm{m}$, less than that of mammalian fibroblast,(37) indicating the smooth side is capable of preventing migration of connective tissue cells across the membrane in vivo. Fibers of the 'rough' side are randomly arranged, creating a porous interface to encourage the attachment and proliferation of osseous cells. CelGro ${ }^{\mathrm{TM}}$ exhibited greater uniformity in arrangement of collagen bundles, and a smoother surface topography, compared to Bio-Gide ${ }^{\circledR}$. Overall porosity and pore size of 
membranes can directly modulate osteogenesis and facilitate cellular seeding, migration and tissue ingrowth (8), (38) $(39,40)$.

In the preclinical rabbit model, micro-CT analysis further confirmed that $\mathrm{CelGro}^{\mathrm{TM}}$ acts in an osteoconductive manner to facilitate cortical bone regeneration. In combination with the autogenous bone graft, use of CelGro ${ }^{\mathrm{TM}}$ leads to significantly increased bone volume and formation of a continuous bony bridge over the defect 30 days post-operatively. By 60 days post-operatively dense and firm mineral precipitation of similar shape and density to healthy cortical bone was observed. In general, autograft without GBR requires approximately 3 months (90 days) to achieve satisfactory bone healing in defects ranging from $4.5 \mathrm{~mm}$ to $6 \mathrm{~mm}$ in diameter on distal femur in rabbits (25)(26). Our result showed that the combination of $\mathrm{CelGro}^{\mathrm{Tm}}$ and autogenous bone grafting results in restoration of mature cortical bone relatively earlier. Histological assessment at 60 days showed that $\mathrm{CelGro}^{\mathrm{TM}}$ with bone graft appears to restore near-normal cortical bone at the defect site. Our study is in contrast with other studies that show delayed or poor/incomplete bone healing in similar sized bone defects in femurs. Lysiak-Drwal K et.al reported a combination treatment of Bio-Oss ${ }^{\circledR}$ Collagen as the void-filler and Bio-Gide ${ }^{\circledR}$ as the GBR scaffold to restore a $5 \mathrm{~mm}$ diameter defect in rabbit femur trochanter(41). This study showed that, over 90 days, the defects were still imperfectly healed, with newly formed, immature bone and connective tissue fibers found locally around biomaterial granules. Ye et.al (42) attempted to develop a decellularized periosteum-covered chitosan globule composite for the treatment of femoral condyle defect in rabbits. At 12 weeks after intervention, large amounts of residual chitosan globule and connective fibrous structure could still be observed in the defect zone. By comparison, our study showed that use of 
CelGro $^{\mathrm{TM}}$ with autologous bone graft appears to achieve better local bone tissue regeneration and accelerates the healing process.

While the results of this pre-clinical study of GBR for cortical bone defects in the rabbit is promising, a limitation of our study is that we were unable to evaluate $\mathrm{CelGro}^{\mathrm{TM}}$ in a clinical trial with an orthopedic indication. Nevertheless, we have demonstrated, a proof of concept clinical study of GBR with CelGro ${ }^{\mathrm{TM}}$ in dental implant placement, that GBR with $\mathrm{CelGro}^{\mathrm{TM}}$ resulted in regeneration of sufficient mature bone to stabilize the dental implants and process to crown placement. In our study, bone quality was assessed as being similar to mature bone 46 months after implant placement at all implant sites. Considering dental implant surgery can be associated with complications leading to patient morbidity and implant failure $(5,6,43)$ including peri-implantitis in $34 \%$ of cases (44) and flap dehiscence in 19.1\%(45), our preliminary result of the clinical study is encouraging. We have seen no complications and successful restoration of bone tissue in GBR by $\mathrm{CelGro}^{\mathrm{TM}}$ in 16 implants among 10 participants

\subsection{Conclusion}

Type I collagen is major protein component of the ECM in bone. It has been shown that undenatured type I collagen has a dynamic, bioactive structure with the ability to regulate cellular proliferation, differentiation and repair $(43,44)$. We showed that CelGro ${ }^{\mathrm{TM}}$ is a predominantly Type I collagen bilayer membrane with two distinct sides of differently-aligned collagen fibers. We established in a preclinical model that the use of $\mathrm{CelGro}^{\mathrm{TM}}$ together with autogenous bone grafting significantly improved cortical bone regeneration compared to autogenous grafting alone. Micro-CT imaging indicated CelGro ${ }^{\mathrm{TM}}$ was superior to a similar comparator membrane, 
Bio-Gide $^{\circledR}$, in terms of cortical bone defect repair, and histological evaluation indicated improved cortical alignment and decreased porosity at the defect site. The clinical study showed that CelGro ${ }^{\mathrm{TM}}$ is effective for bone regeneration in maxillofacial procedures with no adverse outcomes observed. The results of our study suggested that CelGro ${ }^{\mathrm{TM}}$ is ideal membrane for GBR not only in oral maxillofacial reconstructive surgery but also in orthopedic applications.

\subsection{Declaration:}

\section{Availability of data and materials}

The datasets used and/or analysed during the current study are available from the corresponding author on reasonable request.

\section{Ethics approval and consent to participate}

The clinical study was registered at ANZCTR (trial ID ACTRN12615000027516). The ethics approval was from the St John of God Health Care (SJGHC) Human Research Ethics Committee (HREC) approval number 761. Approval was granted on 11 Feb 2015. 
Animal experimental protocols were approved by the Ethics Committees of Kunming Medical University (Approval No. SCXK (DIAN) K2015-0004).

\section{Consent for publication}

All participants enrolled in this study provided written, informed consent and the study protocol were approved by the St John of God Health Care Human Research Ethics Committee.

\section{Competing interests}

One or more of the authors has declared the following potential conflict of interest: $\mathrm{MH}-\mathrm{Z}$ is a scientific consultant to Orthocell Ltd, and holds a patent for CelGro ${ }^{\mathrm{TM}}$ collagen membrane; C$\mathrm{L}$ is a Clinical Research Manager at Orthocell Ltd.

\section{Funding}

Not applicable

\section{Authors'contributions}

$\mathrm{MH}-\mathrm{Z}$ contributed to the conception or design of the work. B-A and C-L contributed to the conduction of the clinical trial; Y-X contributed to the review and analysis of the CBCT image from the clinical trial; R-R and YH-R contributed to the conduction of the preclinical animal study; E-L-B and R-R contributed to the analysis of the data from animal study. E-L-B, T-W, JJ-G and C-L contributed to the analysis and interpretation of characterization data; R-R, N- 
G and MH-Z were the major contributors in data summary and manuscript writing. All authors read and approved the final manuscript.

\section{Acknowledgements}

We thank the Centre for Microscopy Characterization and Analysis (CMCA) at the University of Western Australia for the support in pro- viding instruments for imaging and analysis.

\section{Corresponding author}

Correspondence to Minghao Zheng

\subsection{Reference}

1. Ostrowska M, Maśliński W, Prochorec-Sobieszek M, Nieciecki M, Sudoł-Szopińska I. Cartilage and bone damage in rheumatoid arthritis. Reumatologia. 2018;56(2):111-20.

2. Demontiero O, Vidal C, Duque G. Aging and bone loss: new insights for the clinician. Ther Adv Musculoskelet Dis. 2012;4(2):61-76.

3. Inoue S, Otsuka H, Takito J, Nakamura M. Decisive differences in the bone repair processes of the metaphysis and diaphysis in young mice. Bone Rep. 2017;8:1-8.

4. Guerado E, Caso E. Challenges of bone tissue engineering in orthopaedic patients. World J Orthop. 2017;8(2):87-98.

5. Preethanath RS, AINahas NW, Bin Huraib SM, Al-Balbeesi HO, Almalik NK, Dalati MHN, et al. Microbiome of dental implants and its clinical aspect. Microbial Pathogenesis. 2017;106:20-4.

6. Annibali S, Ripari M, La Monaca G, Tonoli F, Cristalli MP. Local complications in dental implant surgery: prevention and treatment. Oral Implantol (Rome). 2008;1(1):21-33.

7. Retzepi M, Donos N. Guided Bone Regeneration: biological principle and therapeutic applications. Clinical Oral Implants Research. 2010;21(6):567-76.

8. Polo-Corrales L, Latorre-Esteves M, Ramirez-Vick JE. Scaffold design for bone regeneration. J Nanosci Nanotechnol. 2014;14(1):15-56.

9. Krishnan L, Willett NJ, Guldberg RE. Vascularization Strategies for Bone Regeneration. Ann Biomed Eng. 2014;42(2):432-44.

10. Gelse K, Pöschl E, Aigner T. Collagens-structure, function, and biosynthesis. Advanced Drug Delivery Reviews. 2003;55(12):1531-46.

11. Dong C, Lv Y. Application of Collagen Scaffold in Tissue Engineering: Recent Advances and New Perspectives. Polymers (Basel). 2016;8(2):42. 
12. Delgado LM, Bayon Y, Pandit A, Zeugolis DI. To cross-link or not to cross-link? Cross-linking associated foreign body response of collagen-based devices. Tissue Eng Part B Rev. 2015;21(3):298313.

13. Raina DB, Qayoom I, Larsson D, Zheng MH, Kumar A, Isaksson H, et al. Guided tissue engineering for healing of cancellous and cortical bone using a combination of biomaterial based scaffolding and local bone active molecule delivery. Biomaterials. 2019;188:38-49.

14. Landau S, Moriel A, Livne A, Zheng MH, Bouchbinder E, Levenberg S. Tissue-Level

Mechanosensitivity: Predicting and Controlling the Orientation of 3D Vascular Networks. Nano letters. 2018;18(12):7698-708.

15. Taguchi Y, Amizuka N, Nakadate M, Ohnishi H, Fujii N, Oda K, et al. A histological evaluation for guided bone regeneration induced by a collagenous membrane. Biomaterials. 2005;26(31):6158-

66.

16. Turri A, Elgali I, Vazirisani F, Johansson A, Emanuelsson L, Dahlin C, et al. Guided bone regeneration is promoted by the molecular events in the membrane compartment. Biomaterials. 2016;84:167-83.

17. Chan EC, Kuo SM, Kong AM, Morrison WA, Dusting GJ, Mitchell GM, et al. Three Dimensional Collagen Scaffold Promotes Intrinsic Vascularisation for Tissue Engineering Applications. PloS one. 2016;11(2):e0149799.

18. Zheng $\mathrm{M}$, inventorMethod for Producing a Collagen Membrane and Uses Thereof patent US9096688B2. 2015.

19. Zheng $\mathrm{M}$, inventorCollagen Constructs and Method for Producing the Collagen Construct patent US20170216014A1. 2017.

20. Peter Geistlich ZE, Philip Boyne, inventorResorbable collagen membrane for use in guided tissue regeneration1994.

21. Pallela R, Venkatesan J, Janapala VR, Kim S-K. Biophysicochemical evaluation of chitosanhydroxyapatite-marine sponge collagen composite for bone tissue engineering. Journal of Biomedical Materials Research Part A. 2012;100A(2):486-95.

22. Walsh WR, Oliver RA, Christou C, Lovric V, Walsh ER, Prado GR, et al. Critical Size Bone Defect Healing Using Collagen-Calcium Phosphate Bone Graft Materials. PloS one. 2017;12(1):e0168883.

23. Athanasiou VT, Papachristou DJ, Panagopoulos A, Saridis A, Scopa CD, Megas P. Histological comparison of autograft, allograft-DBM, xenograft, and synthetic grafts in a trabecular bone defect: an experimental study in rabbits. Medical science monitor : international medical journal of experimental and clinical research. 2010;16(1):Br24-31.

24. Gruber HE. Adaptations of Goldner's Masson Trichrome Stain for the Study of Undecalcified Plastic Embedded Bone. Biotechnic \& Histochemistry. 1992;67(1):30-4.

25. Becker J, Al-Nawas B, Klein MO, Schliephake H, Terheyden H, Schwarz F. Use of a new crosslinked collagen membrane for the treatment of dehiscence-type defects at titanium implants: a prospective, randomized-controlled double-blinded clinical multicenter study. Clinical oral implants research. 2009;20(7):742-9.

26. Suda KJ, Henschel H, Patel U, Fitzpatrick MA, Evans CT. Use of Antibiotic Prophylaxis for Tooth Extractions, Dental Implants, and Periodontal Surgical Procedures. Open Forum Infect Dis. 2017;5(1):ofx250-ofx.

27. Annen BM, Ramel CF, Hammerle $\mathrm{CH}$, Jung RE. Use of a new cross-linked collagen membrane for the treatment of peri-implant dehiscence defects: a randomised controlled double-blinded clinical trial. Eur J Oral Implantol. 2011;4(2):87-100.

28. Glowacki J, Mizuno S. Collagen scaffolds for tissue engineering. Biopolymers. 2008;89(5):338-

44. 
29. Aamodt JM, Grainger DW. Extracellular matrix-based biomaterial scaffolds and the host response. Biomaterials. 2016;86:68-82.

30. Schlegel AK, Mohler H, Busch F, Mehl A. Preclinical and clinical studies of a collagen membrane (Bio-Gide). Biomaterials. 1997;18(7):535-8.

31. Li S-T. Biologic Biomaterials: Tissue-Derived Biomaterials (Collagen). In: Joyce Y. Wong JDB, editor. Biomaterials: Principles and Practices. London:: CRC Press.; 2012. p. pp. 6.1-6.23.

32. Ginzberg MB, Kafri R, Kirschner M. On being the right (cell) size. Science. 2015;348(6236):1245075.

33. Huang CQ, Carter PM, Shepherd RK. Stimulus induced pH changes in cochlear implants: an in vitro and in vivo study. Annals of biomedical engineering. 2001;29(9):791-802.

34. Reddi BA. Why is saline so acidic (and does it really matter?). International journal of medical sciences. 2013;10(6):747-50.

35. Webb K, Hlady V, Tresco PA. Relative importance of surface wettability and charged functional groups on NIH 3T3 fibroblast attachment, spreading, and cytoskeletal organization. Journal of biomedical materials research. 1998;41(3):422-30.

36. Turkyilmaz I, McGlumphy EA. Influence of bone density on implant stability parameters and implant success: a retrospective clinical study. BMC oral health. 2008;8:32.

37. Li S. Biologic Biomaterials: Tissue-Derived Biomaterials (Collagen). Biomaterials: Principles and Practices. London: CRC Press; 2012. p. 1-23.

38. Gutta R, Baker RA, Bartolucci AA, Louis PJ. Barrier Membranes Used for Ridge Augmentation: Is There an Optimal Pore Size? Journal of Oral and Maxillofacial Surgery. 2009;67(6):1218-25.

39. Zhang K, Fan Y, Dunne N, Li X. Effect of microporosity on scaffolds for bone tissue engineering. Regenerative Biomaterials. 2018;5(2):115-24.

40. Bohner M, Baroud G, Bernstein A, Döbelin N, Galea L, Hesse B, et al. Characterization and distribution of mechanically competent mineralized tissue in micropores of $\beta$-tricalcium phosphate bone substitutes. Materials Today. 2017;20(3):106-15.

41. Lysiak-Drwal K, Dominiak M, Solski L, Zywicka B, Pielka S, Konopka T, et al. Early histological evaluation of bone defect healing with and without guided bone regeneration techniques: experimental animal studies. Postepy higieny i medycyny doswiadczalnej (Online). 2008;62:282-8. 42. Ye Y, Pang Y, Zhang Z, Wu C, Jin J, Su M, et al. Decellularized Periosteum-Covered Chitosan Globule Composite for Bone Regeneration in Rabbit Femur Condyle Bone Defects. Macromolecular bioscience. 2018;18(9):e1700424.

43. Bryce G, Bomfim DI, Bassi GS. Pre- and post-operative management of dental implant placement. Part 2: management of early-presenting complications. British Dental Journal. 2014;217(4):171-6.

44. Kordbacheh Changi K, Finkelstein J, Papapanou PN. Peri-implantitis prevalence, incidence rate, and risk factors: A study of electronic health records at a U.S. dental school. Clinical Oral Implants Research. 2019;30(4):306-14.

45. Kim Y-K, Yun P-Y. Risk Factors for Wound Dehiscence after Guided Bone Regeneration in Dental Implant Surgery. Maxillofac Plast Reconstr Surg. 2014;36(3):116-23. 


\section{Figures}
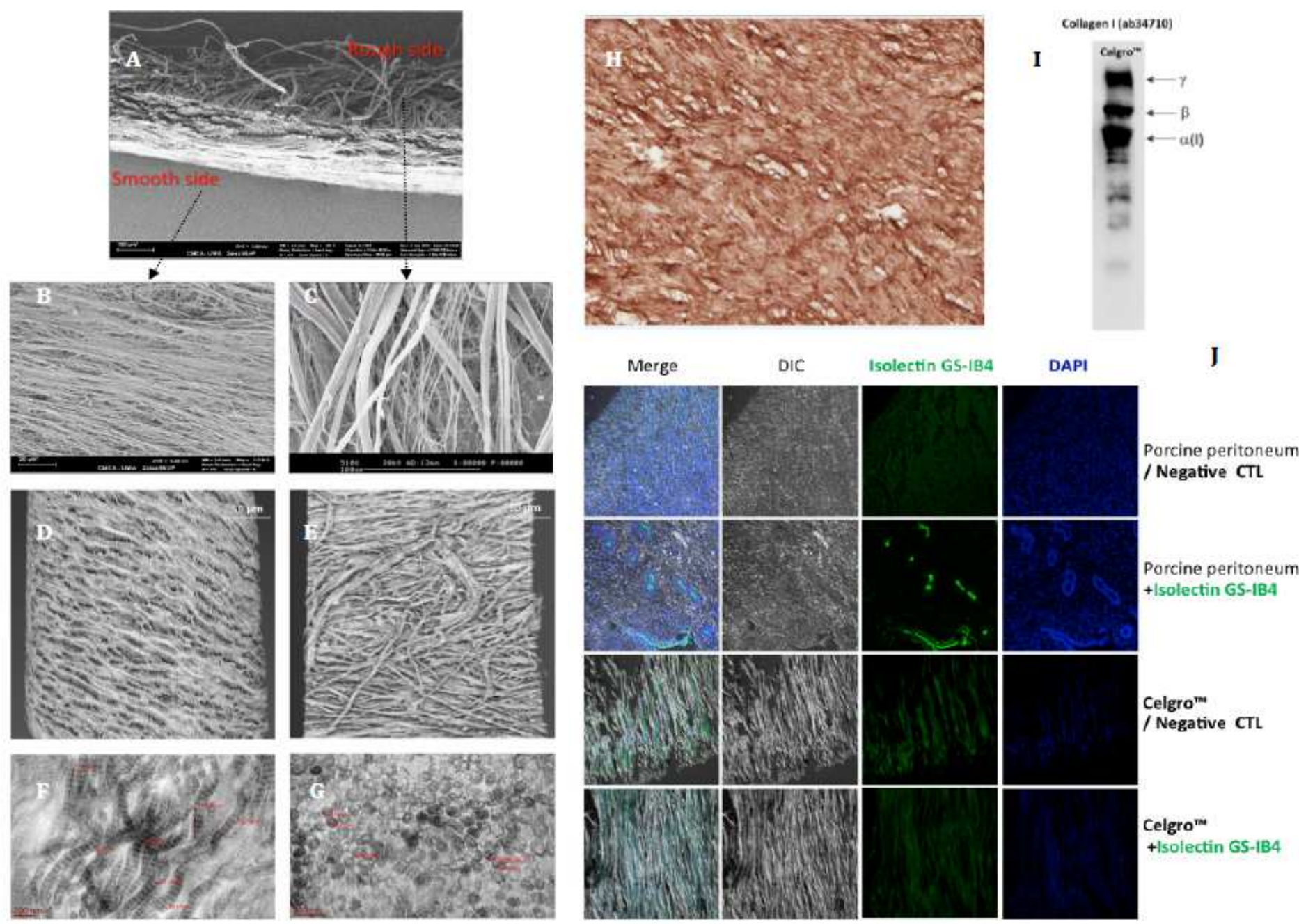

\section{Figure 1}

Characterizations of CelGro ${ }^{\text {TM }}$ membrane. 

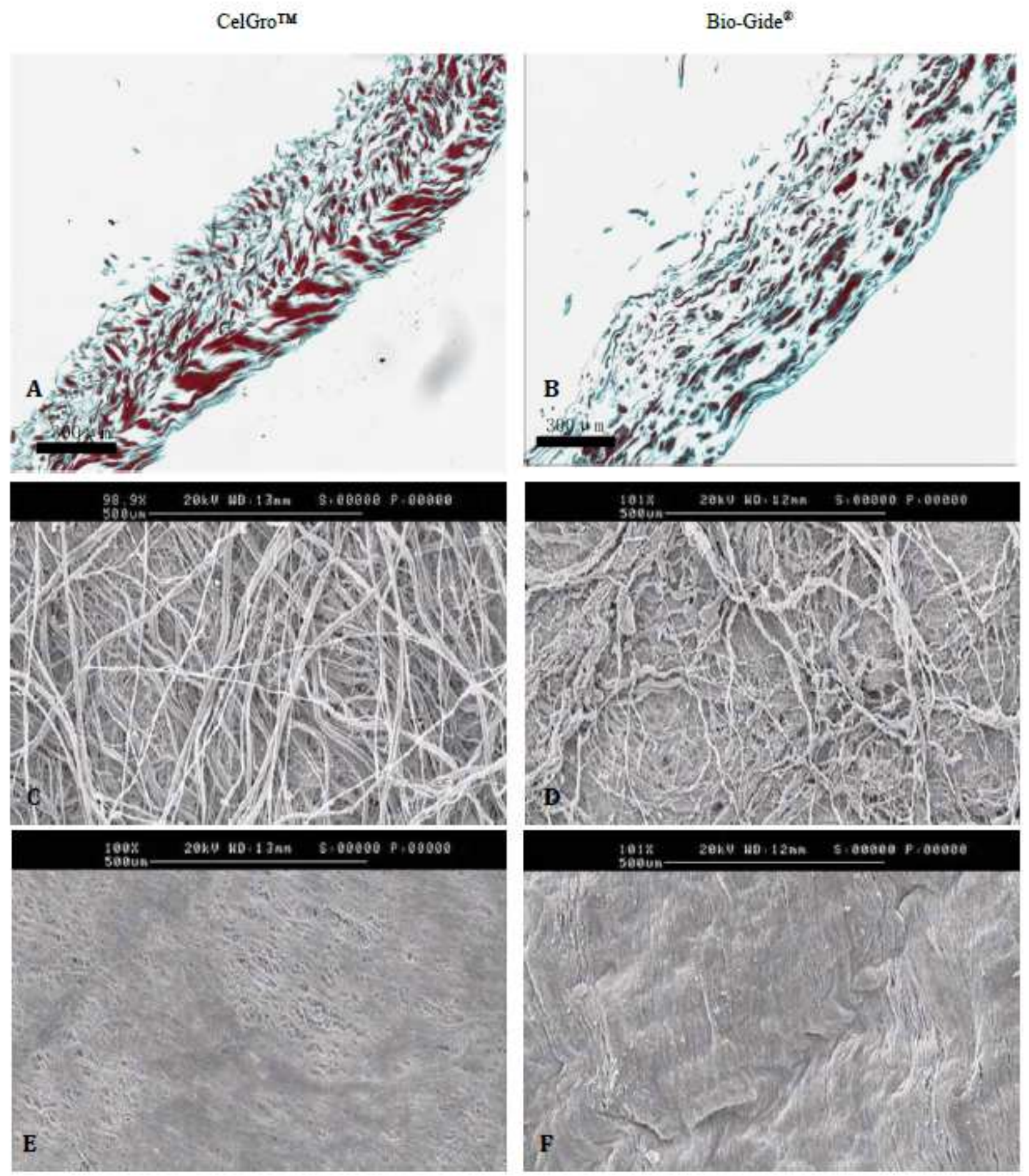

Figure 2

Comparative studies on the morphology of $\mathrm{CelGro}^{\mathrm{TM}}$ and Bio-Gide ${ }^{\circledR}$. Histological morphology of a crosssection of $\mathrm{CelGro}^{\mathrm{TM}}(A)$ and Bio-Gide ${ }^{\circledR}(B)$. SEM image of the rough side of CelGro ${ }^{\mathrm{TM}}(C)$ and Bio-Gide ${ }^{\circledR}(D)$. SEM image of the smooth side of $\mathrm{CelGro}^{\mathrm{TM}}(\mathrm{E})$ and Bio-Gide ${ }^{\circledR}(\mathrm{F})$ 


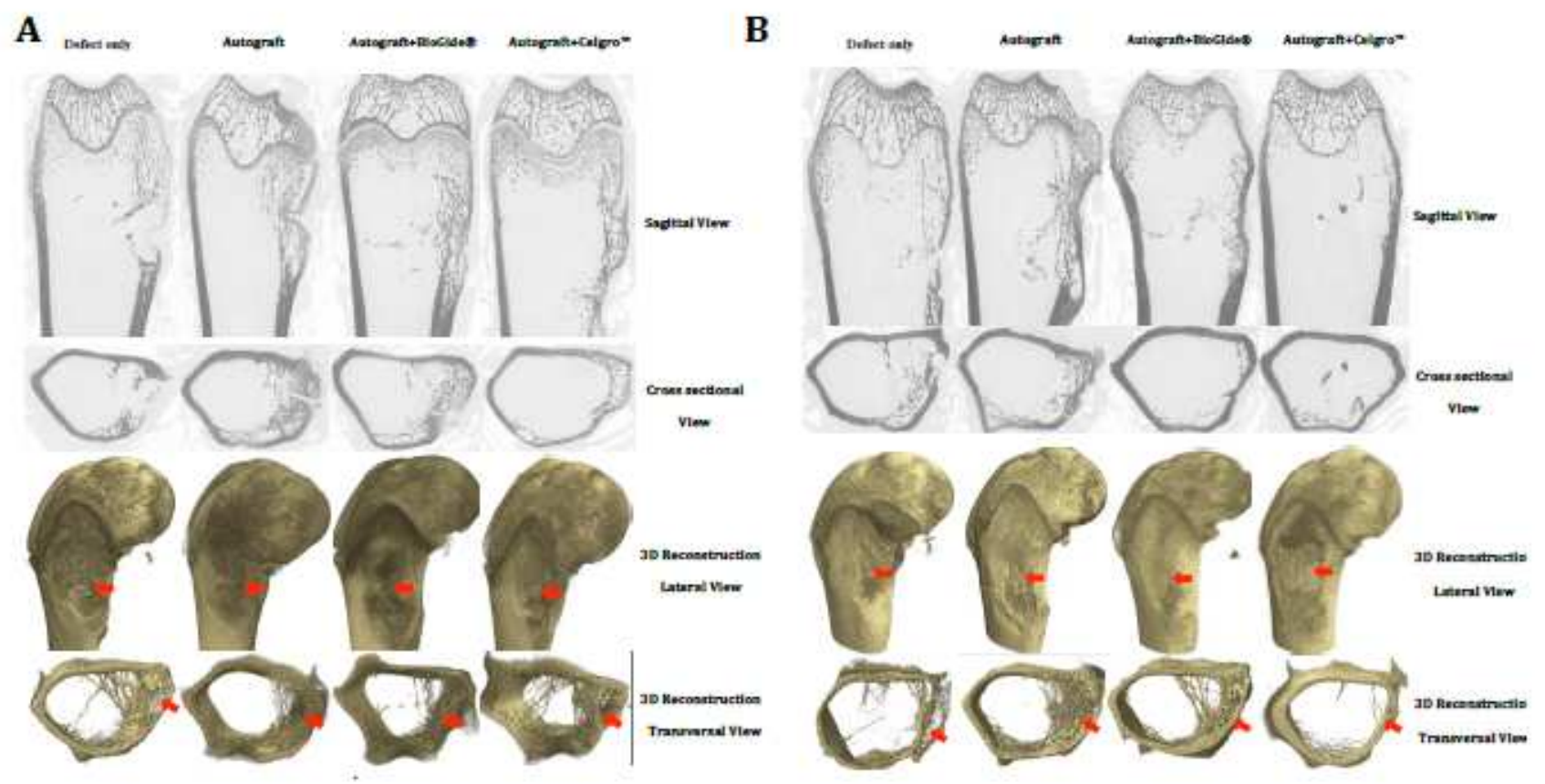

C

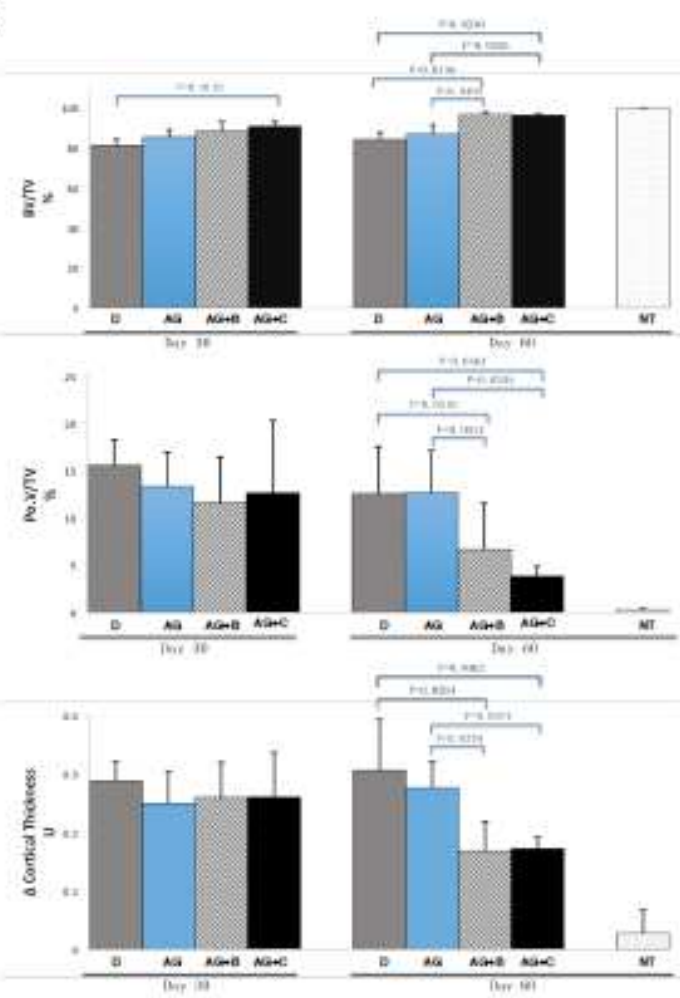

D

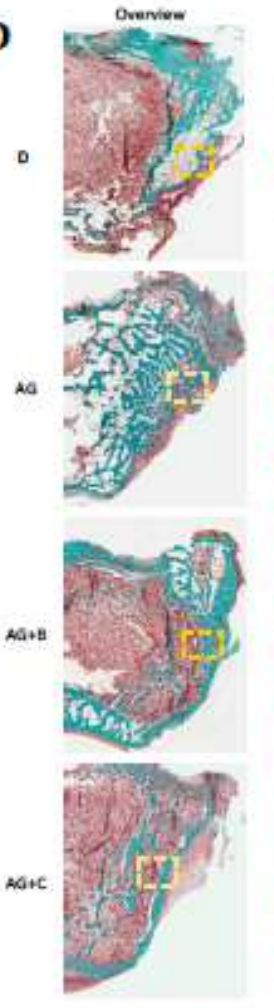

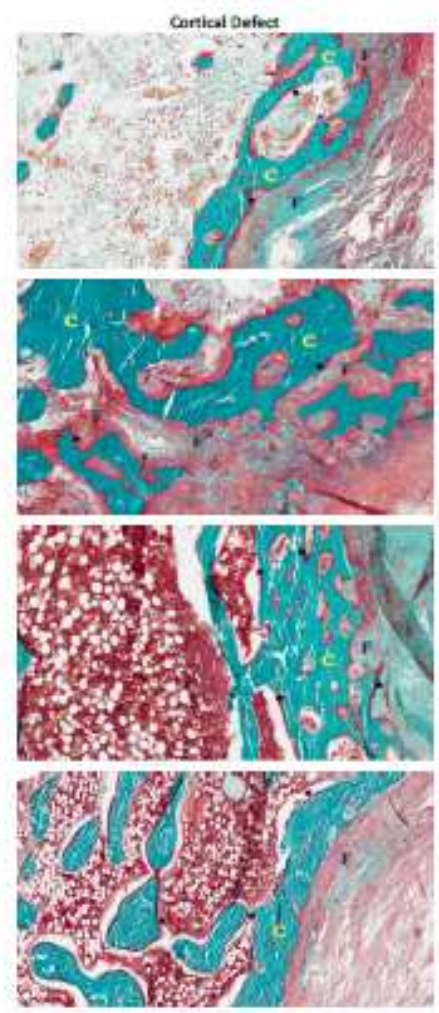

\section{Figure 3}

Preclinical evaluation of the GBR performance in rabbit femoral cortical bone. (A) Representative microCT images of the femur defect at 30 days after surgery. (B) Representative micro-CT images of the femur defect at 60 days after surgery. (C) Micro-CT data of the femur defect model comparing different treatment groups at 30 and 60 days after surgery. (D) Representative histology of the femoral defect showing bone formation in the specimens belonging to groups after 60 days at low and high 
magnification. Legend: The red arrows indicate the cortical bone defect area. Yellow ' $C$ ' indicates newly formed cortex; Purple ' $F$ ' indicates fibrous tissue; * indicates osteoid tissue.

A
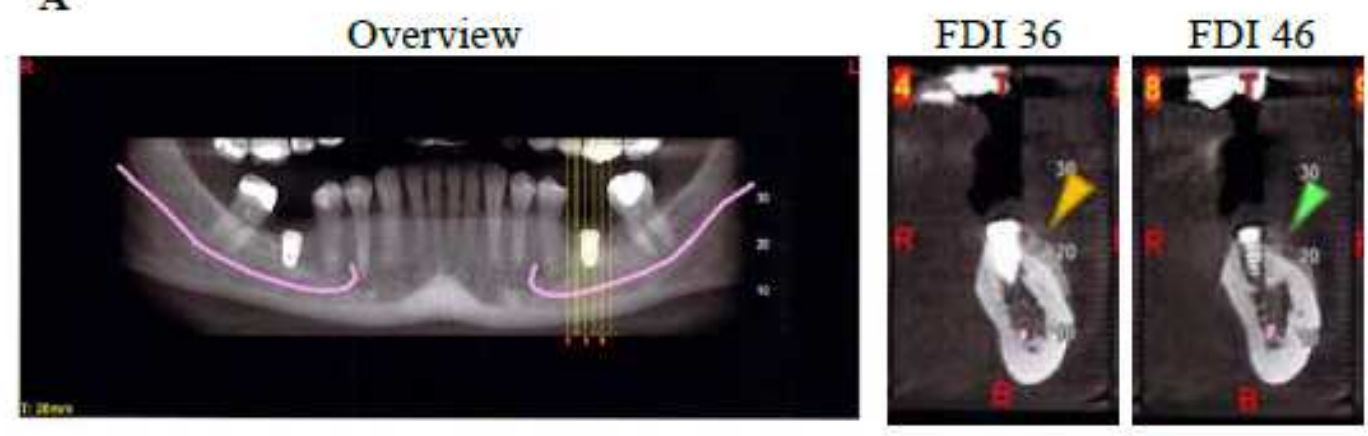

Post-implant

(Visit 2)
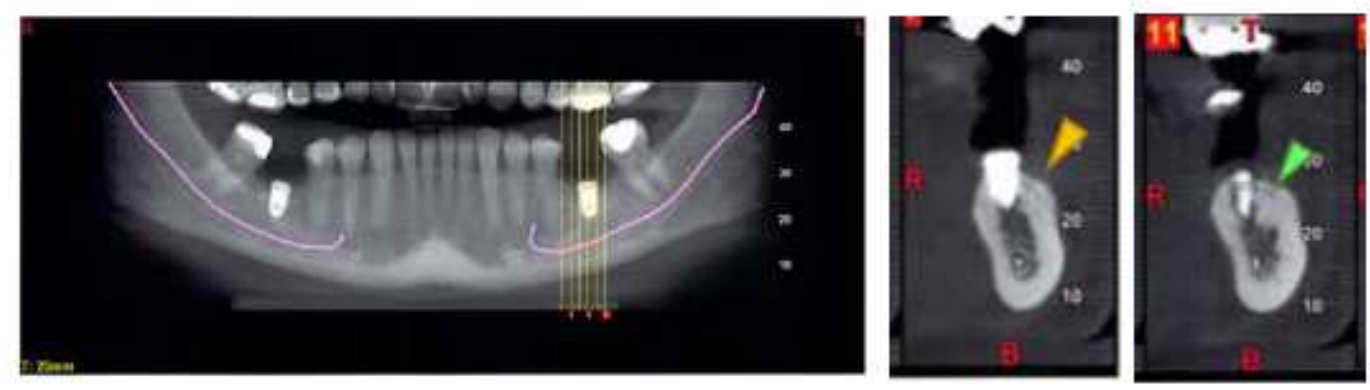

Before Re-entry Surgery

(Visit 4)
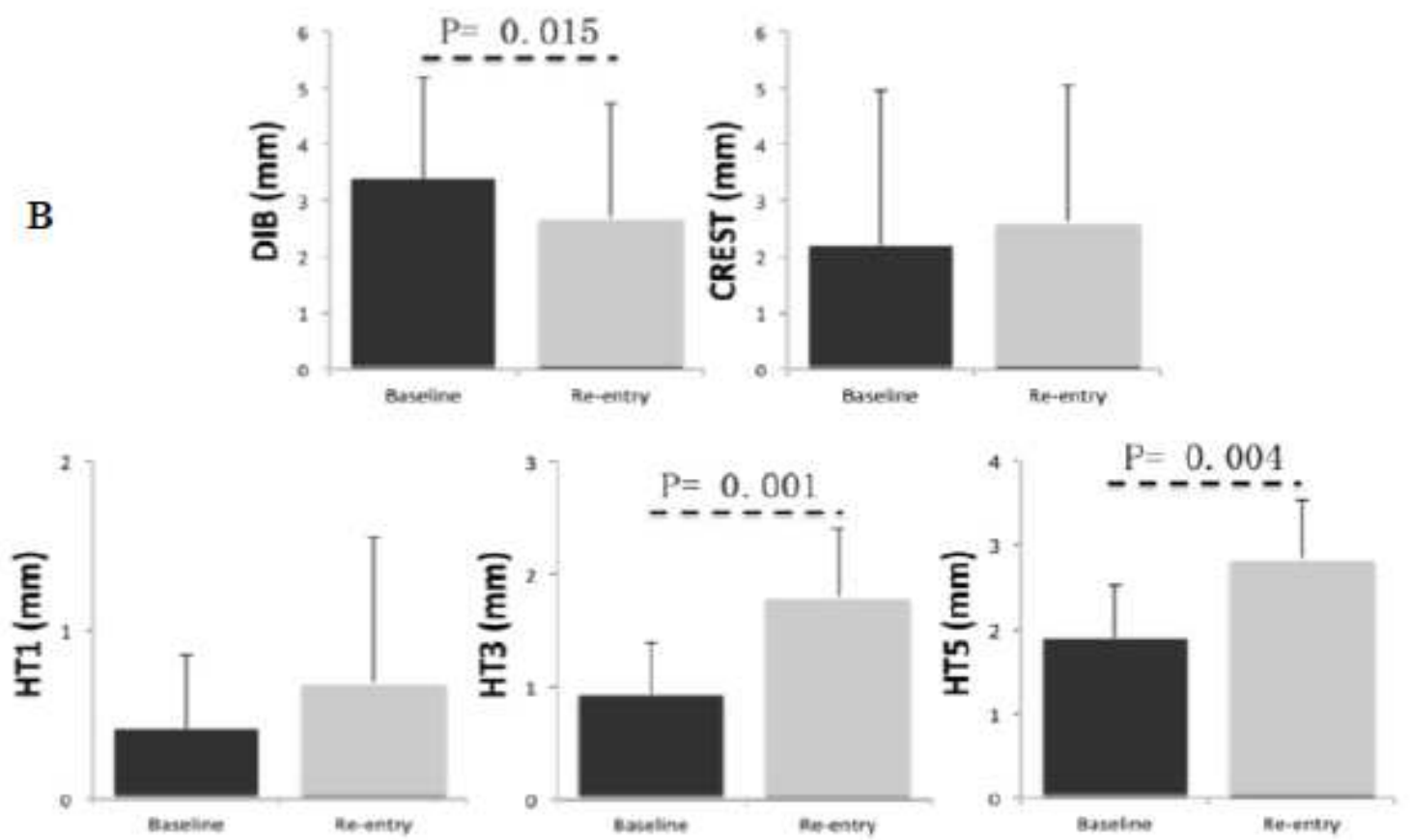

\section{Figure 4}

CBCT results of human proof of concept case series study. (A) Representative CBCT images demonstrating guided bone regeneration at post-treatment time-points of 12 days post-implant (Visit 2) and 6 months (Visit 4). (B) Vertical and horizontal measurements from CBCT of bone regeneration before and after GBR with CelGro ${ }^{\mathrm{Tm}}$. Legend: Yellow arrowheads represent the bone graft material implant site at 
Fédération Dentair Internationale (FDI) site 36; Green arrowheads represent the bone graft material implant site at FDI site 46.

\section{Supplementary Files}

This is a list of supplementary files associated with this preprint. Click to download.

- Table1.pdf

- Supplementarymaterials.pdf 